\title{
Musical and Motor Memory and Its Application in Vocal Practice
}

\author{
Elena Klimenko \\ The Russian State Specialized Academy of Arts \\ Moscow, Russia \\ E-mail: klimenko.ev@gmail.com
}

\author{
Pyotr Glubokiy \\ The Russian State Specialized Academy of Arts \\ Moscow, Russia \\ E-mail: uch-rgsai@mail.ru
}

\begin{abstract}
The authors, being professors at Chair of Vocal Studies, the Russian State Specialized Academy of Art, discuss some principles of work and development of musical and motor memory and its application in vocal practice.
\end{abstract}

Keywords-musical and motor memory; musician; singer; vocal technique; memory development

\section{INTRODUCTION}

Being a peculiar characteristic of human mind, memory is able to retain and recall experiences. It preserves past emotions, feelings, thoughts, movements, etc., creating our life experience. Representations, impressions, thoughts and feelings accumulated by memory become a basis for future actions. We always appreciate a person with personal and borrowed experience in a certain activity. Accumulated by memory knowledge and skills required to perform given tasks set an experienced expert (teacher, artist, doctor, etc.) apart.

Good memory is the one which allows quickly memorizing, retaining for a long time and precisely reproducing the necessary material. A performing musician keeps a large repertory in his memory, its reproduction sometimes taking long hours. This great array of sound and motor connections requires developed musical and motor memory in the context of music performing.

\section{MEMORY PROPERTIES}

The characteristics of memory differ in speed and type of memorization, as well as in information retention period and accuracy of its reproduction. There are some cases of memorizing a text by the first reading, music - by the first listening, etc. However, most of young musicians do not have such a good memory initially. Many beginner singers lack musical and motor memory, so both a teacher and a student should develop the above aspects, along with other general and professional skills.

Information accumulation in memory can be volitional or reflective, with no intention to memorize.

Incidental (involuntary) memory is selective. Everything involved in the sphere of subjective interests is well memorized. We are attentive to the things interesting for us. The stronger inductive stimulus (interest) is, the more sharply defined it is traced in our memory. A musician with no intention to memorize in details a performance he liked often automatically retains in his memory the concert programme, peculiarities of performance, ways of coping with technical difficulties, etc.

However, incidental remembering is not enough for a professional opera singer. When getting prepared for a concert programme or rehearsing his part in a performance, he often has to memorize and handle a massive amount of information which does not cause any incidental interest, and to learn a required things, regardless of its being interesting or not. To stimulate arbitrary memory we need to use special techniques.

\section{DEVELOPMENT OF MEMORY}

Repetition is still the main technique of intentional remembering. But it is useless if there is no special aim to memorize something. Repetition preceded by a strong affirmation for long remembering will enable singers to prolong a retention period of information. To achieve the maximum result repetition should not be unconscious and automatic. Remembering involves intentional reproduction of essential information, the singer each time making the information being remembered meaningful. Thus an interest towards the information being worked on emerges, which actualizes involuntary memory. In case of learning vocal parts, it works better if a detailed analysis of poetic and musical text is made, involving the concept of a musical composition, its form, the meaning of its parts, a structure of melody and accompaniment. Through multiple repetitions students should seek to develop meaningful memorization.

The ability to find semantic links in a certain musical work and links with works performed earlier, using a student's personal experience in vocal performance accelerates the process of remembering and helps retain the given information in his long-term memory. If a student clearly understands the subject matter, each next repetition strengthens semantic links and reveals established connections more vividly. 
The above mentioned can be fully applied to learning vocal techniques. Technical development of singing is hampered by absence of understanding of how sounds are to be produced, with students singing automatically, having no intention to remember and reproduce motor movements. There are some cases when the proper work of a singer's voice apparatus, its being a natural ability or a teaching result, comes to an end in the course of his professional activity. It is often due to absence of his intentional vocal technique, such as established logical connections, understanding of a succession of action and interaction of voice apparatus's parts, tone and other sensations. Firm retention of the proper vocal technique requires remembering of voice sounding, motor movements and diversified sensations.

Remembering includes nervous tension. Multiple repetitions without breaks lead to fatigue. In his book L. Dmitriev, the author of The Fundamentals of Vocal Techniques, notes that singers shouldn't deal simultaneously with numerous vocal techniques and literary texts. Learning process implies one of the fundamental principles of vocal pedagogy - a gradual approach to technical and artistic development. The number of productive repetitions should depend on individual psychophysiological abilities of a student. In practice the best remembering is achieved by regular repetition, i.e. until newly established connections "have been affected by extinctive inhibition - forgetting" $[2$, p.303].

The most frequent and soonest reproduction of the material being learned plays a crucial part in the process of remembering. The accurate reproduction needs psychic activity and is most productive if a student does it with a clear head.

A quality and quantity of the material being learned is quite important. A brief work should be remembered completely, while a large work should be learned by parts, having been analyzed and listened to from beginning to end beforehand.

It is significant to read the music text without making any mistakes. Mistakes are improper connections, which not only slow down the remembering process, as students have to relearn the material, but may also appear afterwards - in a stressful context of a stage performance. This can be applied to motor vocal memory. A composition should be learned in a proper vocal posture, with proper vocal technique.

Reproduction of the learned material, i.e. inclusion of the connections established in the process of learning, may occur involuntarily, at the level of association, or may subject to the volitional order to remember. Involuntary reproduction of the material is a popular thing. Not thinking about it, a singer often silently sings a melody, which came to his mind through incidental connections. At the same time in performing and teaching we always use intentional reproduction, which is stimulated by a volitional order. The set goal - to perform a composition - activates the connections, established in the process of learning. The stronger the connections are, the more accurate reproduction is.

Sometimes the learned material (especially not so large) seems to be digested and ready for accurate reproduction. It is important to avoid a deceptive feeling of complete readiness and not to neglect extra repetitions.

\section{CONCLUSION}

Everybody has his own individual peculiarities of memory. Some of us remember numbers better, others - a melody, still others - words. According to psychologists, there are two main types of memory. The first one, visual memory, is connected with the first signal system, concrete objects and phenomena, and the second one, logical memory, is connected with the second signal system, verbal regulation and mediated perception of the world. The majority of people combine most types of memory. However, profession makes an impact on memory and the area of the most concentrated attention stimulates development of the appropriate analyzers (visual for artists, auditory - for musicians).

When choosing a profession we need to know strong and weak points of our memory and, seeking to harmonious development of both of its types, give preference to the one, which is more efficient for a certain activity. For a singer it is musical (auditory) and kinesthetic (motor) memory.

We should develop a habit to remember, analyze the remembered, retain it in memory and reproduce it accurately. Consistent practice is most likely to evolve all necessary types of memory.

This article discusses just several ways of development of singers' musical and motor memory. Each instance requires an individual approach and pedagogical tools. And intuition based on a practical experience and profound theoretical knowledge will tell you how to act productively.

\section{REFERENCES}

[1] Chaplin V. Physiological Fundamentals of Developing Singer's Voice in the Context of Key Adjustment. Moscow, Informbureau, 2009, $180 \mathrm{p}$.

[2] Dmitriev L. Fundamentals of Vocal Teaching Techniques. Moscow, Muzika, 1968, $675 \mathrm{p}$.

[3] Korolenko T., Frolova G. The miracle of the imagination. Novosibirsk, Nauka 1975, 209 p.

[4] Yakovleva A. Vocal School of the Moscow Conservatory 1866 1916. Moscow, Moscow St. Conservatory, 1999, 107p. 